\title{
El concepto de teodicea racional en el pensamiento de Peter L. Berger
}

Felipe Martin Huete*

Para citar este artículo: Martín Huete, Felipe. «El concepto de teodicea racional en el pensamiento de Peter L. Berger». Franciscanum 162, Vol. LVI (2014): 75-106.

\section{Resumen}

La teodicea aparece como una dimensión psicológica-social de la legitimación religiosa y de las experiencias marginales que constantemente amenazan al hombre. Esta legitimación religiosa viene a realizar una labor de integración entre el poder de explicar y el poder de justificar las situaciones anómicas de la experiencia humana. La integración de tales acontecimientos anómicos en las colectividades hace que el individuo encuentre «un lugar» dentro del esquema general. Es lo que Berger pretende analizar bajo el denominado "fracaso de la teodicea». Se aprecia aquí cómo las situaciones marginales de origen social o natural, en tanto que justificadas en función de unas metas o causas humanas o divinas, pierden su carácter existencial y racional.

Doctor en Filosofía por la Universidad de Granada. Actualmente prepara su tesis doctoral en Sociología por la Universidad Pública de Navarra y es máster universitario en Ciencias de las Religiones. Entre sus artículos publicados, cabe destacar «La función de la religión en la construcción social de la realidad según Peter Berger», en la revista Communio; «ìDónde estaba Dios en Auschwitz?: Del problema de la teodicea al problema de la antropodicea», en la revista $A$ Parte Rei; «Paul Ricoeur y el tránsito gnoseológico del simbolismo a la palabra», en la revista A Parte Rei; «La influencia de Husserl y Heidegger en la hermenéutica filosófico-fenomenológica de Paul Ricoeur», en la revista Bajo Palabra; «Antropología teológica y teología inductiva en Peter L. Berger: la teologización de la conciencia moderna», en la revista Veritas, etc. Actualmente trabaja en la Universidad de Granada, España. Contacto: felipem35@hotmail.es. 


\title{
Palabras clave
}

Teodicea, teología, filosofía de la religión, antropología.

\section{The concept of rational theodicy in the thought of Peter L. Berger}

\begin{abstract}
The theodicy appears as a psychological-social dimension of the religious legitimization and of the marginal experiences that constant threaten the man. This religious legitimization comes to realize a labor of integration between the power to explain and the power to justify the situations anómicas of the human experience. The integration of such events anómicos in the collectivities does that the individual finds < a place $>$ inside the general scheme. It is what Berger tries to analyze under the called one $<$ failure of the theodicy $>$. It is estimated here how the marginal situations of social or natural origin, while justified depending on a few goals or human or divine reasons, they lose his existential and rational character.
\end{abstract}

\section{Keywords}

Theodicy, theology, philosophy of the religion, anthropology.

\section{Introducción}

Berger distingue cuatro tipos de teodiceas racionales: 1) el complejo karma-samsara y sus variantes hinduistas y budistas; 2) el complejo mesiánico-milenarista; 3) la teodicea del dualismo; 4) la actitud masoquista. Del mismo modo, considera que los fenómenos anómicos siguen sin encajar en el orden ontológico, gnoseológico y moral del individuo, pues su funcionalidad contradice cualquier 
intento de integración en el nomos social. Sin embargo, cree que hay intentos de legitimación religiosa (teológicas y filosóficas) que han intentado buscar respuestas y proponer soluciones. A través de ellas, el individuo no se resigna ante la anomia y busca apoderarse de ella, teórica y prácticamente. Es un intento que compagina el afán de integración y de contextualización con el de explicación y justificación. Berger señala que es un intento de rebelarse ante la contingencia y la imperfección de la existencia humana (simbolizada por la muerte), ante el sufrimiento y la injusticia. El individuo no se resigna al desorden o caos autodestructivo, y considera que la razón y el orden sean los principios constitutivos del sentido, del significado; en definitiva, del sistema social nómicamente establecido y legitimado. Siguiendo a M. Weber, Berger considera que hubo un elemento fundamental en la aparición de esta tipología de teodiceas de carácter racional: «la estructura de aquella teodicea con la que la necesidad metafísica de encontrar un significado común a estas tensiones insalvables reaccionó contra la conciencia de su existencia» ${ }^{1}$.

\section{El complejo karma-samsara}

La primera teodicea de tipo racional que Berger desarrolla a través del estudio socio-religioso es la del «karma-samsara» ${ }^{2}$, que consiste en «la ingeniosa combinación de las concepciones del

1 Max Weber, Ensayos sobre sociología de la religión I (Madrid: Taurus 1983), 465. Ver también: Peter L. Berger, "Charisma and religious innovation: the social location of israelite prophecy», American Sociological Review 6, 28, (1963): 940-950. Para Weber existen estos tipos de teodiceas: 1) la escatología mesiánica intramundana, 2) la fe en el más allá, 3) la fe en la Providencia, y 4) la fe en la Predestinación. El problema de la imperfección del mundo queda solucionado por medio de la fe en la predestinación, el dualismo y la transmigración de las almas. Véase: Max Weber, Economía y sociedad (México: Fondo de Cultura Económica, 1964), 413-417; La ética protestante y el espíritu del capitalismo (Barcelona: Península, 1979). Ver también: Peter L. Berger, The social reality of religion (Londres: Faber \& Faber, 1969), 70; y Peter L. Berger, «Motif messianique et processus social dans le Behaisme», Archives de Sociologie des Religions 4, Vol. 4 (1967): 93-107.

2 "La solución formalmente más perfecta del problema de la teodicea la debemos a la doctrina "karma" de la India: es la llamada creencia en la transmigración de las almas (...). Mérito y culpa son retribuidos en el mundo a través de los destinos en una vida futura que el alma atravesará indefinidamente, llevando a una nueva vida una existencia animal, humana o divina (...). El individuo se crea su propio destino, exclusivamente en el sentido más riguroso». Peter L. Berger, The sacred canopy. Elements of a sociological theory of religion (New York: Garden City Doubleday, 1967), 65-68. 
Karma (la ley inexorable de causa y efecto que gobierna todas las acciones, humanas o no, en el universo) y del samsara (la rueda de las reencarnaciones), toda la anomia concebible es integrada en una interpretación abarcante y racional del universo» ${ }^{3}$. La influencia en Berger es aquí evidente en cuanto a las aportaciones de la sociología de la religión de Max Weber, que fue quien caracterizó dicha doctrina.

Según el autor, en esta teodicea específica no se ha abandonado del todo la autonegación del individuo, propia de la teodicea irracional de la participación autotrascendente, pues el individuo es considerado ahora como «un eslabón efímero en una cadena que se extingue infinitamente entre el pasado y el futuro» ${ }^{4}$. Este individuo adquiere en este tipo de legitimación religiosa de trasmigración ${ }^{5}$ un papel ciertamente activo y no meramente pasivo como anteriormente constituía. Esta actividad humana es debida, a juicio de Berger, a que «toda acción humana tiene sus necesarias consecuencias, y toda situación humana es una consecuencia necesaria de pasadas acciones humanas» ${ }^{6}$; es decir, el individuo se crea su propio destino en el sentido más riguroso. Berger considera que los fenómenos anómicos siguen siendo efectos de la finitud y de la contingencia humanas, incluso de un cierto maniqueísmo ético ${ }^{7}$, que viene a configurar desde una retribución en el mundo los destinos de una vida futura. Ahora, el individuo deja de pretender legitimar la anomia a través de la identificación de la totalidad en la colectividad, y pasa a ser él mismo, el garante de sus propias situaciones marginales en tanto que afecciones biográficas, incluso de sus propios méritos y logros. Es decir, «el individuo no puede atribuir a nadie sus desgracias sino a sí mismo e, inversamente, solo puede atribuir su buena suerte

\footnotetext{
Ibíd., 65

Ídem.

El término «trasmigración» es utilizado por Weber para referirse a la concepción del Karma. Peter L. Berger, The sacred canopy. Elements of a sociological theory of religion, op. cit., 65.

Respecto a tal «maniqueísmo ético» Weber considera que la división del mundo en dos principios no consiste, como en la religiosidad providencialista éticamente dual, en el dualismo de la sagrada omnipotencia de lo sagrado frente a la insuficiencia ética de la creaturidad, sino en el dualismo ontológico entre los fenómenos y las acciones del mundo y el ser permanente y en reposo del «orden» eterno y de lo divino.
} 
a sus propios méritos. El complejo karma-samsara proporciona, pues, un ejemplo de una completa simetría entre las teodiceas del sufrimiento y las teodiceas de la felicidad $»^{8}$. Berger señala que una de las diferencias fundamentales entre las teodiceas irracionales y las racionales, va a consistir precisamente en: 1) el vaciamiento de la necesidad de autotrascendencia en la totalidad como identificación con la colectividad (irracional), y 2) la derivación hacía formas de antropodicea (racional), en las que el elemento específico pasa a ser ahora el carácter absoluto de la inmanencia.

Así pues, en el complejo karma-samsara es donde Berger se replantea el problema de la anomia a partir de la idea del pecado individual en cuanto al enraizamiento en la naturaleza humana finita. Esto viene ahora determinado por la vinculación entre las situaciones marginales, la condición humana y la libertad individual. Es decir, Berger cree que el sufrimiento o la felicidad dependen ahora de la sensibilidad del individuo y de las inclinaciones naturales que surgen de ella, que nos hacen responsabilizarnos de su existencia, en tanto que somos nosotros sus originantes. M. Weber dirá que el hombre ya no se encuentra como mera pasividad ante el poder absoluto de lo anómico, sino que, participa en el «reino de la luz» ${ }^{9}$, en el cual se identifica.

La fría racionalidad de esta teodicea ha tenido, según Berger, diversas modificaciones a través de las cuales poder mitigarla o maxificarla. Por un lado, Berger señala el hinduismo popular porque conduce a esta teodicea racional a una identificación con el prototipo irracional de la participación autotrascendente, propia del misticismo de las configuraciones legitimadoras de las estructuras macrocosmosmicrocosmos. Esto es, «la mayoría de estas manifestaciones del hinduismo popular están lejos de la fría racionalidad $»^{10}$. Por otro

8 Peter L. Berger, The sacred canopy. Elements of a sociological theory of religion, op. cit., 65.

9 A juicio de Weber, el «reino de la luz» consiste en una depuración de los procesos anómicos, llevada a cabo mediante esta abarcante y racional interpretación del cosmos, propia de la legitimación religiosa del karma-samsara. También identifica este «reino de la luz» con la «sed de vivir», que se deriva del maniqueísmo ético de buenas y malas acciones respecto al karma, en tanto que, fundamento de la individualización creadora de vida nueva y reencarnaciones.

10 Peter L. Berger, The sacred canopy. Elements of a sociological theory of religion, op. cit., 66. 
lado, Berger indica que el budismo representa probablemente la racionalización más radical de los fundamentos teóricos del karmasamsara. Siguiendo nuevamente a Weber, Berger considera el budismo como la solución más radical de la teodicea. De la misma forma que hizo con el hinduismo, el autor diferencia ahora en el budismo entre: 1) la religiosidad sincrética de las masas y, 2) la religiosidad de los intelectuales, representantes de las verdaderas tradiciones. Estos intelectuales derivan hacia una religiosidad generadora de una «forma eminente de teodicea, tanto por su coherencia, como por el logro metafísico de aunar la redención por el propio esfuerzo, característica de los virtuosos, con la accesibilidad universal de la salvación, el más riguroso rechazo del mundo con la ética social orgánica y la contemplación como vía suprema de salvación con la ética profesional intramundana» ${ }^{11}$.

Debido a esta extrema racionalización de la teodicea del karmasamsara, llevada a cabo por el budismo, Berger considera que hay una depuración radical de todo el universo mitológico-trascendente, siendo sustituido este por una antropologización configuradora del sentido y del significado desde categorías de la inmanencia y de la contingencia. Se erige aquí una defensa de la superioridad de la racionalidad sobre la representación religiosa, como marco de una pretendida antropodicea:

Los dioses y los demonios, la totalidad del cosmos mitológico, los mundos de la imaginación religiosa india, todos ellos desaparecen, no a través de una negativa explícita, sino porque se los considera irrelevantes. Lo que permanece es el hombre, que, sobre la base de la concepción correcta de las leyes del ser (resumidas en las «tres verdades universales»: la anichcha o la no permanencia, la dukkha o la tristeza, y la anatta o la no identidad), se propone racionalmente preparar su propia salvación y ulteriormente alcanzarla en el nibbana (o nirvana) ${ }^{12}$.

Aparece así, la racionalidad cognoscitiva como constructo legitimador del universo, a la vez que desaparece el problema de la 
teodicea, siguiendo las indicaciones de Berger, es decir, «eliminando cualquier intermediario entre el hombre y el orden racional del universo» ${ }^{13}$, de forma que no hay ya lugar para ninguna actitud religiosa, sino solamente para la serenidad del conocimiento y la actividad racional.

Berger señala que hay una variedad de teodiceas fuera de la polaridad tipológica del continuo racional-irracional, que surgen o se establecen «al proyectar una compensación de los fenómenos anómicos en un futuro comprendido en términos mundanos» ${ }^{14}$. En estas teodiceas, la función legitimadora y ordenadora recae en una intervención divina, según la cual, los sufridores serán consolados y los injustos castigados. Según Berger, podemos clasificar dentro de esta categoría todas las manifestaciones del mesianismo religioso, milenarismo y escatología. Berger vuelve a establecer que el sufrimiento (anomia) debe tener un sentido, pues la ausencia de significado es lo que no se puede aceptar. Es necesario explicar los fenómenos anómicos, ya que lo importante va a ser el poder reconciliarnos con el desorden, el poder darle un sentido.

\section{La teodicea mesiánico-milenarista}

La teodicea mesiánico-milenarista relativiza los fenómenos anómicos (sufrimientos, injusticias) del presente, mediante una esperada reconversión de los mismos en un futuro glorioso, es decir, «los fenómenos anómicos son legitimados refiriéndolos a una futura nomización que los reintegrará en un orden significativo

13 Max Weber, Ensayos sobre sociología de la religión I, op. cit., 466.

14 Peter L. Berger, The sacred canopy. Elements of a sociological theory of religion, op. cit., 68. Durkheim considera junto con Berger y Weber, que lo esencial del budismo reside en cuatro proposiciones, que los fieles llaman las cuatro nobles verdades. La primera establece que la existencia del dolor está ligada al perpetuo transcurrir de las cosas; la segunda muestra que la causa del dolor está en el deseo; la tercera hace de la supresión del deseo el único medio de suprimir el dolor; la cuarta enumera las tres etapas por las que hay que pasar para llegar a tal supresión: la rectitud, la meditación y, por último, la sabiduría, la plena posesión de la doctrina. Una vez atravesadas estas tres etapas, se llega al final del camino, la salvación por el Nirvana. Cf. Émile Durkheim, Las formas elementales de la vida religiosa (Madrid: Alianza Editorial, 1993). 
general» ${ }^{15}$. Su carácter de racionalidad deriva de su adecuación y coherencia histórica y, en la misma medida, se la considera potencialmente revolucionaria si la pretendida reconversión anómica de la acción divina es configurada dentro de un marco de acción antropológicamente activo.

Berger observa que la estructura de plausibilidad de este complejo mesiánico-milenarista puede colapsarse en la medida en que aparece lo que él denomina «disonancia cognitiva», según la cual, existen mecanismos cognoscitivos y psicológicos capaces de racionalizar la negación de una evidencia empírica, esto es, un desmentido de la experiencia. Del mismo modo, el autor considera que este tipo de teodiceas utilizan un recurso que las capacita para la inmunización ante tal disonancia cognitiva. Este recurso consiste en un «refinamiento» que da lugar a teodiceas intermedias, en las cuales, la salvación, redención o compensación son extrapoladas en términos de «un otro mundo» ${ }^{16}$. Esto va a plantear, a juicio de Berger, una escatología de la historia, que gira en torno a conceptos de futuro, compensación y línea fronteriza con el presente, y en donde esta escatología estaría en condiciones de aguardar históricamente la historia, de mantenerla abierta. Surge una valoración teológica del «tiempo» que es específica de estas teodiceas mesiánico-milenaristas, junto con la idea de que la historia (relación del tiempo presente y del futuro glorioso) y el proceso histórico están orientados hacía una meta prometida en «un otro mundo». Esto es lo que autores como J. Moltmann, siguiendo el discurso bergeriano, considera cuando dice: «La nomización queda localizada en la otra vida» ${ }^{17}$.

Según Berger, la verdadera categoría de la historia en dicho complejo mesiánico-milenarista no es ya el pasado o lo efímero, sino la «futuridad». Las percepciones interpretativas de la historia se configuran de acuerdo a concepciones futuristas y escatológicas,

15 Peter L. Berger, The sacred canopy. Elements of a sociological theory of religion, op. cit., 69.

16 Berger considera que frente a la teodicea mundana del complejo mesiánico-milenarista, esta teodicea de la extraterritorialidad y del alejamiento de la contingencia de la creaturidad es más conservadora que revolucionaria.

17 Jürgen Moltmann, Teología de la esperanza (Salamanca: Sígueme, 1989), 338. 
es decir, «si el sentido de la historia es esperado del futuro y es concebido como misión del presente, entonces la historia no es una trama de necesidades y legalidades, ni la palestra de un capricho absurdo. El futuro como misión sirve de mediador entre el encargo presente y la decisión de hoy y lo real-posible; remite, en lo real, a posibilidades abiertas ${ }^{18}$.

Este complejo mesiánico-milenarista lleva a cabo, según Berger, una interpretación particular de la esperanza que es conservada en una esfera transpuesta, empíricamente inaccesible. La esperanza aparece aquí como lo «otro», como aquello que no alcanzamos a pensar ni imaginarnos, basándonos en el mundo actual y en nuestras propias experiencias empírico-existenciales vividas en él. Esta «esperanza» se presenta como algo nuevo y como promesa de un futuro asentado en la divinidad. Estos enunciados de la promesa que llevan en sí el discurso de la esperanza, tienen que entrar en colisión con la realidad experimentable en el tiempo presente. No son resultado de experiencias pasadas, sino que conforman la condición de posibilidad de experiencias futuras. Es decir, «no pretenden iluminar la realidad que está ahí, sino la realidad que viene» ${ }^{19}$. Así pues, este complejo de teodicea plantea el problema del horizonte escatológico de futuro, apelando a unos presupuestos metahistóricos y extraterritoriales de configuración nómica, a través de los cuales pueda quedar establecida la pretendida legitimación religiosa del «orden establecido» y sus derivados fenómenos anómicos. Berger deriva de esta interpretación un concepto fundamental que desarrollará la «teodicea del dualismo»: la fe escatológica.

\section{La teodicea del dualismo}

Otra clase de teodicea perteneciente a la tipología racional, y que es estudiada por Berger es la «teodicea del dualismo». Del mismo 
modo que la categoría definidora e identificativa de las teodiceas del complejo mesiánico-milenarista era, a juicio de Berger, la relativización de los fenómenos anómicos en un futuro glorioso, en «un otro mundo», ahora, en esta teodicea dualista la categoría que la define de forma específica viene determinada por un maniqueísmo ético, en el que «los fenómenos anómicos son por supuesto, atribuidos a las fuerzas malignas o negativas, mientras toda nomización es comprendida como una victoria progresiva del antagonista bueno o positivo» ${ }^{20}$. Además, a diferencia del carácter masoquista que comportaban las teodiceas de la participación autotrascendente respecto de la pasividad del individuo, así como de su total negación de la autoidentidad, ahora el individuo se autoidentifica a través de la actividad participativa que le confiere el maniqueísmo ético, en la búsqueda de la redención.

Surge un dualismo que intenta ofrecer una solución sistemática y meditada del problema de la imperfección del mundo. Este dualismo está configurado como una lucha entre el espíritu y la materia:

Este mundo, como realidad material, era la creación de fuerzas negativas, identificadas por los cristianos gnósticos con la divinidad del Antiguo Testamento. Y como la divinidad positiva no fue la que creó este mundo, no se le puede responsabilizar por sus imperfecciones. Por consiguiente, los fenómenos anómicos de este mundo no deben entenderse como molestas intromisiones del desorden en el ordenado cosmos, sino que, por el contrario, este mundo es el reino del desorden, de la negatividad y del $\operatorname{caos}^{21}$.

Aparece aquí una notable influencia weberiana, pues este autor hablará de la sempiterna coexistencia y contraposición de los poderes de las tinieblas, de la mentira, de la impureza y de la maldad a los poderes de la luz, de la verdad, de la pureza y del bien. De este modo, según Berger, la redención propia de estas teodiceas consistirá en el exilio de este mundo que es definido como sede de las imperfecciones, constituía una novedad inaudita en el contexto del mundo del antiguo próximo oriente. Era el Dios "totalmente distinto" de la realidad natural de la experiencia humana, inhallable tanto en el interior del hombre, como en el interior del mundo». Peter L. Berger, A rumor of angels: Modern society and the rediscovery of the supernatural (New York: Garden City, Doubleday), 101. 
de la injusticia, del sufrimiento, del pecado, de la contingencia y de la caducidad, de una cultura necesariamente cargada de culpa y carente de sentido, para instalarse en el reino de la luz, del espíritu ${ }^{22}$.

Berger escenifica los niveles de acción y de legitimación de este tipo de teodiceas, pues identifica la anomia con el universo empírico, inacabado y negativo; al contrario que el nomos, que se configura en la extraterritorialidad y lejanía del universo empíricamente determinado. Pero lo verdaderamente importante de este tipo de teodiceas es, según Berger, su confrontación con la estructura de plausibilidad de los monoteísmos radicales, y especialmente el monoteísmo bíblico, pues «este tipo de monoteísmo se enfrenta -y lo consigue o fracasa- con su propia capacidad para resolver el planteamiento de la teodicea: "¿Cómo es posible que Dios permita...?" ? $^{23}$. Según este tipo de monoteísmo bíblico, Dios no tiene

22 Berger hace uso aquí de la «teología de la desdicha» weiliana, según la cual, la conducta que impide una vida de espera de Dios es el excesivo apego a este mundo. La teología weiliana considera que el «desapego» tenía que ser un componente esencial de la fe cristiana. Desapego significa para Simone Weil: «Vaciar el deseo, la finalidad, de todo contenido, desear en vacío, desear sin anhelo. Separar nuestro deseo de todos los bienes, y esperar. La experiencia nos enseña que dicha espera es fructífera. Se adquiere entonces el bien absoluto», Simone Weil, La gravedad y la gracia (Madrid: Trotta, 1994), 64. Berger participa también del concepto weiliano de «destrucción del yo» como forma de escapar del sufrimiento de este mundo: «La destrucción puramente exterior del yo es dolor casi infernal. La destrucción exterior a la que el alma se asocia por el amor es dolor expiatorio. La producción de ausencia de Dios es dolor redentor». Simone Weil, Cuadernos II (Madrid: Trotta, 1972), 251-252. Influenciado por el pensamiento de Weil, Berger en sus obras A rumor of angels y Questions of faith establece una serie de principios definitorios de su teodicea masoquista-dualista: 1) La relativización de los fenómenos anómicos en un «otro mundo»; 2) Establece un maniqueísmo ético donde el mal es igual a unas fuerzas malignas o negativas y el bien (nomización) fuerzas positivas; 3) El individuo siempre busca la redención; 4) Surge un dualismo que ofrece una solución al problema de la imperfección del mundo; 5) Identifica la anomia (caos) con el universo empírico, inacabado y negativo, al contrario que el nomos, que se configura en la lejanía del universo empíricamente determinado; 6) desarrolla la plausibilidad del monoteísmo como forma de explicar el problema del mal: «El mal es constitutivo del mismo Dios»; 7) Las construcciones soteriológicas o redentoras no son susceptibles de desmentido empírico: «Dios (bien) contrapuesto al mundo (mal)». Cf. Max Weber, Economía y sociedad, op. cit., 116. Según Weber: «La división del mundo en dos principios no consiste, como en la religiosidad providencialista éticamente dual, en el dualismo de la sagrada omnipotencia de Dios, frente a la insuficiencia ética de toda criatura; ni tampoco como en el dualismo espiritualista, en la división de todo el acontecer en luz y tiniebla, en espíritu claro y diáfano y en materia tenebrosa y turbia, sino en el dualismo ontológico entre los fenómenos y acciones fugaces del mundo, y el ser permanente en reposo del "orden" eterno y de lo divino". Cf. Peter L. Berger, «Charisma and Religious Innovation: The Social Location of Israelite Prophecy», op. cit.

23 Peter L. Berger, The Sacred Canopy. Elements of a Sociological Theory of Religion, op. cit., 73. Para desarrollar el problema de Dios y su permisibidad o no ante el mal en el mundo, ver también Peter L. Berger, «Reflections on law and order», Christianity and Crisis 21, Vol. XXVIII (1968): 298-299. 
la culpa del mal, sino que este reside en la materia o en el demiurgo creador del mundo. De este modo, estas teodiceas dualistas chocan con la idea judeocristiana que defiende un monoteísmo estrictamente divino y el creacionismo desde la nada. Berger considera que Weber define, acertadamente, -en su obra Economía y sociedad (1944)- el concepto negativo de Dios que impera en este tipo de teodicea: «Este dualismo es incompatible con el monoteísmo bíblico y con la convergencia de bien y ser en la divinidad; sin embargo, permanece de forma mitigada en la concepción del Dios justiciero, que castiga a los malos iy a los buenos si se descuidan! $»^{24}$. Berger, por el contrario, señala el aspecto más positivo y redentor de este Dios: «Dios revela su auténtico poder, incluyendo el poder de triunfar sobre el pecado y sobre la muerte $»^{25}$. Apuesta por el rechazo del dualismo de forma más existencial que intelectual, pues puede resultar insoportable la idea de un Dios malo y cruel, que sería la mayor objeción posible a la global concepción humana de sentido.

Así pues, este dualismo llevaría consigo la resignación al mal como algo irrebasable y genuinamente constituyente, en la medida en que se asume el mal como constitutivo del mismo Dios. Esta identificación entre el mal y Dios, ha posibilitado dos modos de interpretar esta concepción teológica: la primera interpretación considera que «la amenaza del absurdo de la vida humana lleva a rechazar esta tipología y a buscar la solución por otro lado, aunque no sea más que por medio de una dialéctica que, en última instancia, supere el dualismo» ${ }^{26}$; la segunda interpretación teológica estaría configurada -afirma Berger-por lo que Leibniz definió como el «ojo de Dios» ${ }^{27}$, es decir, la integración del monoteísmo bíblico con la

24 Max Weber, Economía y sociedad, op. cit., 465

25 Peter L. Berger, A far glory: The quest for faith in an age of credulity (New York: Free Press, 1992), 6.

26 Juan Antonio Estrada, La imposible teodicea (Madrid: Trotta, 1997), 36.

27 Leibniz identificó el Dios de la revelación con el Dios de la razón. El Dios de la revelación se muestra como el Dios de la razón y no al revés. Según Leibniz, es una muestra de la debilidad humana no creyente poner en duda la sabiduría y la bondad de Dios creador a causa de la presencia del pecado y del mal en el hombre y en el mundo. Su intención es la de justificar la bondad de Dios ante el mal del mundo debido a la libertad del hombre. 
racionalidad sistemática. Según esto, Leibniz defiende que no hay incoherencia lógica entre la existencia de Dios y la del mal. De aquí deriva el autor racionalista la tesis según la cual, Dios ha creado el mejor de los mundos posibles, porque siempre está obligado a elegir voluntariamente lo mejor en cuanto a su atributo de perfección. Surge entonces la paradoja a partir de la cual hay un distanciamiento del antropocentrismo cristiano, puesto que, el que Dios escoja lo mejor no implica que lo sea para el hombre. De esta segunda interpretación teológica surge el concepto bergeriano de «teología ajena», según la cual -siguiendo un determinismo teológico schleiermacheriano y weiliano- el hombre está en manos de Dios:

Con esta denominación se ponía de relieve que nuestra salvación no se
encuentra en nuestras propias manos, sino que es algo realizado integra-
mente por Dios. La acentuación de este hecho, por supuesto, constituyó
el núcleo de la reforma protestante, al insistir en la primacía de la gracia
y rechazar la «salvación por las obras» ${ }^{28}$.

Otro factor determinante respecto a la ruptura con el monoteísmo bíblico que Berger considera dentro de esta tipología de teodiceas es precisamente el desarrollo de la escatología bíblica, desde las expectativas históricas concretas hasta las construcciones soteriológicas no susceptibles del desmentido empírico. Es aquí donde aparece una concepción religiosa determinista de la historia, en donde lo contrapuesto al Dios que obra históricamente es el «mundo», sometido al poder del mal. Esta configuración escatológicoapocalíptica, se dirige a la superación del mal por el bien, y se dirige también a que «el mundo sometido al poder del mal» sea sustituido por el mundo de la justicia, como ya indicó Albert Camus ${ }^{29}$. En este sentido, Berger señala que la crisis de plausibilidad del cristianismo va acompañada por una constante desvaloración de su teodicea. Es esta actitud escatológica la que va a permitir la relación entre la teodicea bíblica y la teodicea masoquista.

28 Peter L. Berger, A far glory: The quest for faith in an age of credulity, op. cit., 14.

29 Según Berger, Camus es el gran representante de la crisis de plausibilidad de la teodicea cristiana, especialmente cuando defiende el cambio del reino de la Gracia por el reino de la justicia. 


\section{Las teodiceas de actitud masoquista}

Por último, Berger analiza el proceso dialéctico y religioso que emerge en las teodiceas de actitud masoquista de raíz bíblica ${ }^{30}$, en donde "un "otro" se enfrenta al hombre como una objetiva y poderosa realidad» ${ }^{31}$. Esta dialéctica toma el cariz particular de la órbita bíblica debido a la radical trascendentalización de ese «otro», que es concebido Dios todopoderoso, totalmente justo y creador ${ }^{32}$. Es un Dios que trasciende al mundo y se manifiesta simbólicamente desde una radical alteridad ${ }^{33}$.

Berger cree que es en esta trascendentalización donde se revela la alteridad del numen divino (Dios), y se manifiesta como misterio fascinante y tremendo, además de donde se encuentra la solución masoquista por excelencia al problema de la teodicea: la sumisión a lo totalmente «otro». Esto es lo que ya Schleiermacher, antes que Berger, denominó «el sentimiento de dependencia del Absoluto», que pasa a ser un sentimiento de reverencia y sorprendente ante las experiencias subjetivas acordes a la divinidad. El hombre se remite ahora a Dios «el otro divino» y trascendente como realidad primigenia y fundante. Esta dependencia humana se lleva a cabo porque Dios actúa «soberanamente por encima de cualquier ética

Berger deja bien claro que su desarrollo de la teodicea bíblica está totalmente influenciado por Weber, aunque también muestra su sorpresa al comprobar cómo Weber centra su análisis en la actitud radicalizada de esta actitud masoquista, específicamente en la doctrina cristiano-calvinista de la predestinación.

31 Peter L. Berger, the Sacred Canopy. Elements of a Sociological Theory of Religion, op. cit., 73.

32 El concepto de creación está estrechamente unido al concepto de Dios trascendente y único. Se trata de dos conceptos de la misma idea que se complementan y esclarecen mutuamente.

33 Según Berger, la comprensión de las relaciones Dios-mundo es la clave para la recta comprensión de la esencia divina y sus propiedades. Así pues, Dios en virtud de su carácter incondicionado y de la infinita plenitud del ser es, por una parte, totalmente distinto al mundo, infinitamente superior a él, total y absolutamente trascendente; y, por otra parte, es omnipresente a ese mundo, rigiéndolo todo y estando en él de un modo inmanente pleno. Esta dialéctica de la relación ontológica Dios-mundo es una tesis de la doctrina filosófica tradicional acerca de Dios. San Agustín la definió de este modo: «Espero que quien piensa espiritualmente ya habrá visto claro que ni una sola naturaleza puede ser opuesta a Dios. Porque si él es, y ello solo de Dios se puede predicar sin más, es que Dios no tiene nada como opuesto. Si se nos preguntase que es opuesto de caliente, responderíamos que frío; preguntados por lo contrario de rápido, contestaríamos que lento, y así sucesivamente. Pero si se pregunta por lo opuesto de lo que es, la respuesta correcta sonará: lo que no es». San Agustín, «De fide et símbolo», en Obras completas XXXIX (Madrid: Biblioteca de Autores Cristianos, 1988), 7, PL 40, 185. 
humana y cualesquiera principios nómicos generales» ${ }^{34}$. Este carácter masoquista que se presenta en la dialéctica con el «otro» todopoderoso y trascendentalizado, va a derivar en lo que Weber denominó «fe en la providencia y en la predestinación» ${ }^{35}$, en la cual, la solución va a consistir en trazar una inaudita distancia ética entre el Dios del más allá y los hombres que viven bajo el dominio del pecado $^{36}$. Este Dios trascendente y absconditus se encuentra más allá de las pretensiones éticas de los hombres, y sus designios están totalmente fuera del alcance del hombre. El «topos» originario de esta técnica de salvación es lo que Weber llamó la "profecía emisaria», la cual exige, según Weber, una «ética de la convicción» con una determinada concepción de Dios: un Dios activo, justiciero y exigente.

Dentro de esta teodicea masoquista, Berger distingue dos desarrollos de dicha actitud; uno más radical y otro menos duro. Respecto al primer desarrollo, -el más radical-, lo centra dentro de las teorías y concepciones de la predestinación, basándose esencialmente en los fundamentos «religiosos» de la ascética intramundana del calvinismo que fueron desarrollados por Max Weber ${ }^{37}$. Este autor señalaba que «la exaltación calvinista respecto al inexorable designio de Dios, que desde toda la eternidad ha elegido unos pocos hombres para salvarse y ha relegado a otros muchos a un destino "infernal", es probablemente la culminación de la actitud masoquista en la historia de la religión ${ }^{38}$. Según esta postura radical, todo está ya previamente "predestinado"; la suerte de este mundo, como la suerte después de la muerte, está ya decidida de antemano por Dios. Todo depende de la fe de la providencia. Según Weber, esto lleva a que desaparezca el

34 Peter L. Berger, The Sacred Canopy. Elements of a Sociological Theory of Religion, op. cit., 74

35 Max Weber, Economía y sociedad, op. cit., 414s.

36 «No se puede recurrir a la naturaleza finita del hombre para explicar el pecado, porque entonces ya no sería un mal moral. El hombre no sería culpable de que Dios lo hubiera creado de esta forma y el pecado revertiría sobre el creador, como un agente indirecto. En realidad, se exculparía al mal moral en consideración a la debilidad de la naturaleza humana creada por Dios, con lo que indirectamente se cuestionaría por qué Dios ha creado así al hombre, ya que si el pecado es inevitable, el hombre estaría exento de culpa moral». Juan Antonio Estrada, La imposible teodicea, op. cit., 249.

37 Peter L. Berger, The Sacred Canopy. Elements of a Sociological Theory of Religion, op. cit., 75.

38 Weber desarrolla esta temática en su obra La ética protestante y el espíritu del capitalismo (Barcelona: Península, 1979). 
problema de la teodicea de raíz, pues Dios, en tanto creador y único artificio de la predestinación, no necesita de ninguna justificación ante sus criaturas, todo es gratuito; y, en segundo lugar, se lleva a cabo una máxima racionalización, siendo eliminada toda magia sacramental, aunque sigue albergando tensiones entre Dios y el mundo, entre el «deber ser y el ser», tal como distinguía San Agustín.

Berger considera el desarrollo calvinista de la predestinación como la parte más radical de la actitud masoquista de la teodicea bíblica, justamente porque el dogma calvinista de dicha predestinación se fundamenta en la trascendencia y la absoluta gratuidad de Dios:

La exaltación calvinista respecto al inexorable designio de Dios, que desde toda la eternidad ha elegido a unos pocos hombres para salvarse y ha relegado a otros muchos a un destino «infernal», es probablemente la culminación de la actitud masoquista en la historia de la religión ${ }^{39}$.

Este Dios calvinista es un Dios trascendente, que creó y gobierna el mundo y que está fuera del alcance de la inteligencia humana, pudiendo ser solo conocido a través de la predestinación. La influencia de Max Weber en el pensamiento bergeriano se hace aquí notoriamente presente, pues, este señala que la doctrina calvinista -aun conociendo un doble concepto de Dios: el «Dios revelado», el Dios benigno y bondadoso del Nuevo Testamento; y el «Dios absconditus», el Dios déspota que obra arbitrariamente-, se centra en la concepción del Dios déspota del Antiguo Testamento. Weber lo indicó del siguiente modo: «La consecuencia lógica del interés religioso de Calvino es, por tanto orientado tan solo a Dios y no a los hombres, pues Dios no es por los hombres, sino los hombres son por y para Dios, y todo cuanto sucede ${ }^{40}$.

Para Berger, -influenciado por Weber-el concepto de predestinación calvinista, presentaba un problema psicológico decisivo por resolver: nadie podía saber si pertenecía o no al grupo de los elegidos, es decir, todo creyente tenía que plantearse necesariamente estas cuestiones:

39 Peter L. Berger, The sacred canopy. Elements of a Sociological Theory of Religion, op. cit., 75.

40 Max Weber, «La ética protestante y el espíritu del capitalismo», en Ensayos sobre sociología de la religión $I$, op. cit., 90. 
¿He sido yo elegido?, ¿cómo estaré seguro de ello? Tales cuestiones relegaban a segundo término toda preocupación terrena ${ }^{41}$. Esto daba lugar a plantearse la cognoscibilidad del estado de gracia, es decir, un interés en conocer si se pertenece o no al número de los elegidos. De este modo, la actitud que debía adoptar el individuo era la de seguir una «Consecuencia lógica» a partir de la cual, la única vía de disposición para acercarse a su Dios lejano y trascendente era considerarse como un «instrumento de Dios» a través de la «ascesis intramundana», en sentido weiliano. Aquí se encuentra, a juicio de Berger, la mayor polaridad que se establece entre el hombre y Dios, dentro de esta actitud masoquista y de «teología ajena», pues «la soberanía de Dios y la negación del hombre alcanzan aquí un terrible climax en una visión de los condenados que se adhieren a la glorificación del mismo Dios que los ha sentenciado» ${ }^{42}$.

Berger indica que la pregunta de la teodicea es repetida hasta el punto de convertirse en una acusación abierta contra Dios. Pero la respuesta que se nos da no es racional y su único objetivo es el de argumentar ad hominen, es decir, procede a plantearse el problema del mal a partir de la idea del pecado original ${ }^{43}$. De esta forma, toda su argumentación está dirigida a confrontar al hombre con el mal ${ }^{44}$, para

41 Para más información, Ibíd., 81.

42 Peter L. Berger, The Sacred Canopy. Elements of a Sociological Theory of Religion, op. cit., 75. A juicio de Berger, aparece aquí, un concepto fundamental dentro de la teodicea, el concepto de «Gracia de Dios»: «The question What is God's Grace? Concerns how the individual got into Christianity and what got into the individual when he or she became a Christian... is a question about the individual seeing himself in scripture...» en Peter L. Berger, «On the conceptualization of the supernatural and the sacred», Dialog 17, (1978): 36-42.

43 Se podría hablar del «pecado original» como de un metadogma, un símbolo con significado pragmático.

44 «El hombre se convierte así en el agente del mal y el responsable último de los sufrimientos. Estos, a su vez, se convierten en instrumentos de purificación, en causa de mérito ante Dios y en medios para adquirir virtudes y madurar progresivamente individual y colectivamente». Juan Antonio Estrada, La imposible teodicea, op. cit., 37. Sobre el origen del mal o de la maldad en el mundo, señala Béla Weissmahr cuatro concepciones: 1) El mal es uno de los principios básicos del mundo, que desde toda eternidad se opone al principio del bien. Los dos principios originarios que se identificaron con la materia y con el espíritu; 2) En opinión de Schopenhauer, el mal es el condicionante esencial del universo, por cuanto que en el mundo se deja sentir un anhelo originario nunca satisfecho; 3) Los estoicos intentaron resolver el problema del mal negando su realidad objetiva: en el fondo el mal no existe, solo es una sensación meramente subjetiva del hombre; 4) Del concepto judeo-cristiano de Dios deriva la idea de que el mal no fue originariamente un elemento constitutivo del mundo, sino una secuela de la autonomía criatural y en concreto el resultado de la voluntad libre y finita. No se puede concebir el mal como la última determinación fundamental del mundo, porque el mal en su esencia no se puede ni concebir ni conocer sin el bien. Cf. Béla Weissmahr, Teología natural (Barcelona: Herder, 1986). 
así descargar de culpa a Dios. Siguiendo el método teológico-moral kantiano, Berger indica que desaparece el problema de la teodicea y es sustituido por un problema de antropodicea, pues, como diría Kant:

El fundamento de ese mal no se puede poner en la sensibilidad del hombre ni en las inclinaciones naturales que surgen de ella (...). No nos está permitido responsabilizarnos de su existencia, ni tampoco podemos, porque en cuanto congénitas no somos nosotros sus originantes. Sin embargo, la propensión al mal, que concierne a la moralidad del sujeto (y que se presente con él y en él, en cuanto que esencia que actúa libremente), debe achacársele como algo de lo que él mismo es culpable, a pesar de su profundo enraizamiento en el libre albedrío, a causa del cual debemos decir que se encuentra en la naturaleza del hombre ${ }^{45}$.

La relación del masoquismo religioso con el Dios bíblico, la encuentra Berger en el mito de Job, gracias al influjo determinante de la filosofía moderna (Hume, Kant, Hegel, Kierkegaard, Jaspers, Buber, Bloch, Kolakowski, Ricoeur, etc.). Finalmente, el autor presenta la teodicea bíblica, con dos figuras paradigmáticas del primero y del segundo testamento: Job y Jesucristo. Job tenía tanta fe, tanta confianza en Dios que decía: «Aunque Él me mate, aun así lo glorificaré. Él debe estar matándome por mi propio bien», dijo Job. «Dios sabe lo que hace, nosotros no sabemos lo que decimos», dice la sabiduría popular religiosa. Berger considera que es aquí donde tiene lugar la consumación de la sumisión masoquista inherente de esta teodicea, pues, Job simboliza a todos los hombres en la experiencia del sufrimiento. Otros autores -como Ernst Blochresaltan la arbitrariedad demoníaca de Dios, contraponiéndolo al hombre que anhela ser libre y dador de sentido ${ }^{46}$. Berger considera que en la figura de Job se da un retroceso con respecto al Dios de Abraham, al que se le considera una imagen equívoca en la conciencia religiosa popular. Surge, pues, la problemática clásica

Inmanuel Kant, La religión dentro de los límites de la mera razón (Madrid: Alianza, 1981), 44. Kant será el autor que más claramente formulará el fracaso de las teodiceas del siglo xviII. En Kant se produce un giro copernicano: el «mal radical» se encuentra dentro de la naturaleza específicamente humana, la cual, supone la posibilidad, por medio de la razón y la libertad, de poder elegir entre el bien y el mal. Para más información, cf. Rogelio Rovira, Sobre el fracaso de todo ensayo filosófico en la teodicea (Madrid: Universidad Complutense, Facultad de Filosofía, 1992).

Cf. Ernst Bloch, El ateísmo en el cristianismo (Madrid: Aguilar, 1983). 
del hombre enfrentado al Dios maligno: la angustia ante un mal omnipresente y atormentante; es una angustia existencial que reclama la muerte como evasión. Es un Dios que se sitúa detrás del dolor, del mal, de la injusticia y que hace del propio hombre (Job) el instrumento de sus designios. La pregunta de la teodicea es una acusación abierta contra Dios, lo que constituiría la respuesta no racional a la teodicea.

Berger cuestiona, por el contrario, si por esta vía se alcanza una racionalización teológica o filosófica del mal. Según el autor, esto está simbolizado en los amigos de Job y en su concepción tradicional del sufrimiento como un castigo por el pecado. Esta justificación del mal establece que hay una relación directa entre el sufrimiento humano y el pecado. Los amigos de Job defienden la proporcionalidad entre el sufrimiento humano y el pecado. De igual modo, defienden el concepto de un Dios omnipotente y bueno. Por tanto, la conclusión a la que estos llegan es: «Lo que le ocurre (a Job) tiene que ser justo, porque viene de Dios; el sufrimiento debe ser racionalmente aceptado y asumido acríticamente ${ }^{47}$.

Berger distingue entre el problema de la teodicea y sus respuestas no racionales que derivan en una impugnación de la idea clásica de Dios, frente al problema de la antropodicea y sus respuestas racionales que derivan en una retribución de Dios y de la experiencia del mal, que a su vez deriva en una universalización de la experiencia del propio mal.

Una vez que ha expuesto las bases de la actitud masoquista «más radical» de esta teodicea bíblica, se centra ahora en desarrollar los fundamentos de la actitud masoquista «menos dura», los cuales, «tienen más posibilidades de arraigar en la religión de las masas» ${ }^{48}$. Berger considera que el elemento que distingue la actitud más pura del masoquismo, de la actitud menos pura es que este incluía la

\footnotetext{
47 Peter L. Berger, The sacred canopy. Elements of a sociological theory of religion, op. cit., 75 ss. Para más información cf. Juan Antonio Estrada, La imposible teodicea, op. cit., 82.

48 Peter L. Berger, The Sacred Canopy. Elements of a Sociological Theory of Religion, op. cit., 75
} 
esperanza ${ }^{49}$ en una vida futura, en la que «el Dios que castiga dejará un día de castigar y su aceptación en medio de las penas dejará paso a un tipo de glorificación más dichosa» ${ }^{50}$.

Se rompe con el rigor masoquista por medio de interpretaciones teológicas del sufrimiento ${ }^{51}$ que intentan una justificación de Dios ante los argumentos deshumanizantes del sufrimiento. Berger señala que esta transformación se llevó a cabo en el judaísmo, en el cristianismo y en el islamismo y, de modo especial, en el calvinismo. Estos intentos de dulcificar la sumisión masoquista, hacen posible que la dialéctica del individuo con el «otro» de la divinidad, intente buscar un punto de interacción. De este modo, la teología judía, por ejemplo, pretende corregir los mitos clásicos para solidarizar a Dios con las víctimas, contra aquellos que pretenden justificar el sufrimiento inmerecido del inocente. Se recurre a una apologética divina que remite al Dios creador que se impone al caos e impone un orden bueno, así como su carácter de impugnable del cosmos ante el hombre se empequeñece: la creación es considerada una obra divina y como tal buena. Aunque se trate de una creación perfecta y consumada, pues, Dios es garante de un mundo con orden y sentido para el hombre:

A lo largo de la mayor parte de la historia, los hombres han creido que, de una forma u otra, el orden de la sociedad se corresponde con un orden subterráneo universal, un orden divino que sostiene y justifica todas las tentativas realizadas por el hombre en busca de un orden. (...) Desaparecido este orden, tanto el grupo como el individuo se sienten amenazados por el más fundamental de los terrores, el terror al $\operatorname{caos}^{52}$.

Pero según Berger, «estas "mitigaciones" de la teodicea masoquista pierden importancia histórica si se las compara con la esencial solución

49 Lo más válido de esta actitud, a juicio de Berger, es su esperanza de futuro, su inconformismo ante el presente, el rechazo a la facticidad como lo último, la postulación de la historia como abierta y no cerrada en sí misma.

50 Peter L. Berger, The Sacred Canopy. Elements of a Sociological Theory of Religion, op. cit., 76.

51 La intencionalidad de estas «teologías del sufrimiento», tanto judía como cristiana, es coherente con un Dios solidario con el hombre. Las especulaciones de estas teologías sobre la presunta esencia divina, a la luz del mal y del sufrimiento, son proyecciones y antropomorfismos con los que el hombre intenta justificar a Dios. Juan Antonio Estrada, La imposible teodicea, op. cit., 397.

Peter L. Berger, A rumor of angels: Modern society and the rediscovery of the supernatural, op. cit., 60. 
cristiana del problema, que es la postulada en la cristología» ${ }^{53}$. El autor destaca, pues, la teodicea propuesta por el cristianismo, dentro del continuo de racionalidad-irracionalidad de las teodiceas históricas. Esta teodicea cristiana está basada en la figura del Dios encarnado y del Dios crucificado, ya que «sin la agonía de la Cruz, la Encarnación por sí sola no aportaría una solución al problema de la teodicea» ${ }^{54}$.

Berger, en The sacred canopy (1967), se refiere a la concepción de Albert Camus ${ }^{55}$ sobre dicha teodicea cristiana -en tanto que cristología-, y cita estas palabras del pensador existencialista francés:

En cuanto Cristo sufrió, y sufrió por su propia voluntad, el sufrimiento ya no pudo ser considerado como injusto y todas las penas devinieron necesarias. En un cierto sentido, la amarga intuición del cristianismo y su pesimismo respecto a la conducta humana, se basa en la presunción de que la injusticia general satisface tanto al hombre como la justicia total. Solo el sacrificio de un Dios inocente podía justificar la universal y prolongada tortura de los inocentes. Solo el más abyecto sufrimiento infligido a Dios pudo suavizar la agonía del hombre. Si todas las cosas en el cielo y en la tierra, sin ninguna excepción, están condenadas al dolor y al sufrimiento, entonces era posible una extraña forma de felicidad ${ }^{56}$.

Berger cree que el descubrimiento de un Dios omnipotente y bueno, creador del mundo y dueño de la historia, tenía necesariamente que suscitar la pregunta más radical de la teodicea. Bajo estas palabras de Berger, se puede ver un trasfondo teológico que influyó de forma determinante en el autor, nos referimos a la teodicea dualistamasoquista de Simone Weil y de Albert Camus. Esta influencia

53 Peter L. Berger, The Sacred Canopy. Elements of a Sociological Theory of Religion, op. cit., 76.

54 Ibíd., 76.

55 Albert Camus ha sido uno de los autores más comprometidos con el problema del mal físico y moral, desde la identificación con los que lo padecen. Según el propio autor, la teodicea cristiana fracasa porque resulta imposible aceptar a un Dios que permite el sufrimiento de los niños, de los inocentes. El sin sentido del dolor es insalvable para poder afirmar a Dios, pues no es posible creer en el creador de un universo inaceptable, en el que reina el dolor. Su interpretación de la historia está vinculada a las tradiciones bíblicas, pero desde una lectura antropocéntrica no teísta: la historia humana es una revuelta «metafísica porque contesta con fines del hombre y de la creación». Camus es consciente de la necesidad humana de Dios, pero también de su imposibilidad. El hombre necesita a Dios pero no puede creer en él. No asume la religión como mera dadora de sentido, sino como fundamento mismo de la lucha contra el mal. Pero es imposible encontrar a Dios en un mundo inundado de mal. Cf. Juan Antonio Estrada, La imposible teodicea, op. cit., 321-323.

56 Albert Camus, The Rebeld (New York: Vintage, 1956), 34; Peter L. Berger, The Sacred Canopy. Elements of a Sociological Theory of Religion, op. cit., 77. 
se plasma, fundamentalmente, en la cristología de Berger: «El descubrimiento de Cristo implica el descubrimiento de la presencia redentora de Dios en medio de la angustia de la experiencia humana. Dios es percibido así no como una realidad terriblemente opuesta al hombre, sino como una realidad que está presente en el mismo como amor sufriente ${ }^{57}$. Esta entrega de Dios al mundo como forma de justificar el mal (teodicea), es heredada de la teologia weiliana. Simone Weil en su obra Attente de Dieu (1966), señala que la verdad acerca de Dios es que no solo invita a los seres humanos a someterse a la necesidad (sufrimiento físico consustancial al mundo), sino que, en un inmenso amor, también él mismo se entrega completamente a ella. La crucifixión de Jesús es un acto, indica Weil, de suprema obediencia al mal presente en el mundo y al sufrimiento del hombre. La conclusión que extrae Weil al respecto es que el sufrimiento que existe en el mundo no se debe a que Dios no posea el poder de cambiarlo o la bondad para desear que cambie. Dios nunca concibió el universo como un lugar en el que ejercer sus poderes, sino que más bien, Dios se inhibe deliberadamente de actuar en él. Solo a través de la desdicha personal se hace transparente la verdad acerca de Dios, y solo entonces alcanzamos un mejor conocimiento de la naturaleza del amor de Dios. Weil creía que en la voluntad de Dios de someter a Jesús a la desdicha radica la verdad más importante acerca de su amor por el mundo. Retomando el problema clásico del mal, escribió:

O Dios no es todopoderoso o no es absolutamente bueno, o no ejerce su domino en todo lo que está bajo su poder. Así pues, la existencia del mal en el mundo, lejos de ser una prueba contra la realidad de Dios, es lo que nos la revela en su verdad ${ }^{58}$.

De la misma forma, ya antes del pensamiento de Camus y Weil, en la teoría anselmiana encontramos cómo la muerte de Cristo es absolutamente necesaria, para pagar la deuda y restaurar el orden sin interferir en la inmanencia de la creaturidad. La encarnación de Dios posibilita, según San Anselmo, la actuación desde dentro

57 Peter L. Berger, A Rumor of Angels: Modern Society and the Rediscovery of the Supernatural, op. cit., 104.

58 Simone Weil, A la espera de Dios (Madrid: Trotta, 2000), 91. 
del orden creado y la Cruz permite actuar en consonancia con la esencia divina que exige la justicia y ejerce misericordia con la humanidad caída sin alterar el orden mundano. En San Anselmo también podemos apreciar, fielmente, la sentencia bergeriana, según la cual, «la relación exacta entre el Dios que castiga y el Dios que sufre debía ser formulada en la doctrina cristológica. Solo si ambas vertientes de Dios, la plena humanidad y la plena divinidad del Cristo encarnado, podían ser mantenidas simultáneamente, la teodicea apoyada en la Encarnación podía ser totalmente plausible» ${ }^{59}$, y la sentencia categórica de las cristologías ortodoxas, según las cuales, el sufrimiento de Cristo podía ser considerado como un sufrimiento del mismo Dios, siendo a la vez un dolor genuinamente humano ${ }^{60}$.

Esto es así, porque en la doctrina anselmiana, la Cruz -que es la máxima irracionalidad desde la perspectiva del hombre justo entregado a Dios-, se convierte en el signo de la máxima consecuencia y racionalidad humana. De la misma forma que el Dios encarnado es el culmen de la ontoteología anselmiana, para Weil, la encarnación es la presencia de Dios en la belleza del mundo. Así pues, como afirma la teoría anselmiana, ya no interesa tanto el personaje histórico, cuanto Cristo como Dios encarnado. Es decir, se parte del Hijo de Dios y de su descenso en la encarnación para culminar en la cruz. Por el contrario, la cristología ascendente ${ }^{61}$, que estudia cómo Jesús recorre un camino histórico que culmina en la cruz y que le revela como hijo de Dios a partir de la resurrección, queda marginada.

59 Peter L. Berger, The Sacred Canopy. Elements of a Sociological Theory of Religion, op. cit., 77.

60 «La decisión salvífica es ambigua, está contaminada de muerte. En última instancia, Dios se "venga" del deseo pecador. Se hace hombre él mismo, con lo que posibilita el deseo humano de ser como Dios. Pero su contrapartida es la muerte, primero como pago por el pecado, luego como satisfacción. Desde este esquema, se puede afirmar que Cristo muere por dos deseos convergentes de Dios y del hombre: al anhelo humano de ocupar el lugar de Dios es implícitamente deseo de muerte (la de Dios). La expectativa divina es la doble muerte: el pecador, por haber pecado, y del no pecador, para que el hombre recobre la vida». Cf. Juan Antonio Estrada, La imposible teodicea, op. cit., 154.

61 Se conoce por «cristología ascendente» o «cristología desde abajo» al momento teológico que reconoce metodológicamente que la fe en Cristo tiene que estar vertida también y especialmente desde el principio, debajo de la historia. Es decir, existen dos modos de acceder al misterio de Cristo: 1) partiendo de su divinidad y «descendiendo» hasta la humanidad (Cristología descendente); 2) partiendo de la humanidad y «ascendiendo» hasta la divinidad (Cristología ascendente). 
Como señalaba antes, Berger distingue dos vertientes dentro de la teodicea cristiana: la primera, estaría configurada por la teodicea cristológica; la segunda, estaría configurada por la teodicea de la $\mathrm{Cruz}^{62}$. De este modo, Berger señala que para establecer una estructura de plausibilidad, así como una solución al problema de la teodicea -desde la perspectiva cristiana-, ambas subteodiceas ${ }^{63}$ deben ser mantenidas simultáneamente. Las connotaciones que se derivan son históricas, pues en la historia del cristianismo podemos señalar dos periodos: el primero, corresponde al primer milenio del cristianismo, en el que la cristología descendente acentuó el plan salvífico global (Cristo se encarna para divinizarnos y murió para librarnos de la muerte, del pecado); el segundo, corresponde al segundo milenio del cristianismo, que partiendo de la doctrina anselmiana, se centra en la teodicea de la cruz en cuanto encarnación de Dios. Pero el problema consistía, a juicio de Berger, en establecer el requisito indispensable, por el cual, el hombre participa de la redención del sacrificio de Cristo: el reconocimiento del pecado. Weil al igual que Berger, mantenía una relación entre la cruz, el pecado y la cristología descendente. Según esta autora, la cruz representa el árbol del pecado y de la verdad, además de ser el camino por el cual Dios desciende al hombre:

$\mathrm{El}$ árbol de la vida fue un madero. Algo que no produce frutos, sino un movimiento vertical. Es preciso que sea levantado el hijo del hombre, para que os atraiga hacia él. Es posible matar dentro de sí la energía vital conservando únicamente el movimiento vertical. Las hojas y los frutos son un derroche de energía cuando lo único que se pretende es subir ${ }^{64}$.

Nadie consigue escapar de la cruz, pero puede haber distintas formas de soportarla. Podemos cargarla por obligación como Simón

«La cruz cristiana, irrevocablemente colocada en la historia humana, revela las derrotas provocadas por el pecado de los hombres a través de las cuales avanza el proceso de la redención hacía una nueva vida. Pero no queremos hacer de esa cruz el símbolo del sin sentido de la historia ni renunciar a nuestra identificación con un movimiento histórico en pro de la justicia, pretendiendo en nombre de la cruz, que todos los esfuerzos históricos son fragmentarios y problemáticos». Cf. Gregory Baum, Religión y alienación (Madrid: Cristiandad, 1980); Peter L. Berger, Questions of Faith. A Skeptical Affirmation of Christianity (New York: Blackwell Publishing, 2004), 85-97.

63 Me refiero al masoquismo duro y al masoquismo menos duro.

64 Simone Weil, La gravedad y la gracia, op. cit., 128. Para ver la importancia que Simone Weil tuvo en el pensamiento místico de Berger, cf. Peter L. Berger, Questions of Faith. A Skeptical Affirmation of Christianity, op. cit., 7-13. 
el Cirineo. Esto supone un peso mayor, sin sentido, absurdo. O la asumimos para ayudar a los otros a cargar sus cruces pesadas, como María, en el camino del calvario o al pie de la cruz junto a su Hijo Bendito. O actuamos como Jesús, que cargó el «peso de nuestros pecados» para la salvación de la humanidad, un gesto de solidaridad con todos aquellos que sufren con el peso de la condición humana. De este modo, la cruz puede tener el sentido de la entrega amorosa, libre y caritativa y podemos completar con nuestro sufrimiento lo que está faltando para la salvación de la humanidad. Berger recurre a la «solución agustiniana» del problema de la teodicea, la cual pretende una «transferencia profundamente masoquista de la cuestión de la justicia divina a la de la condición pecadora del hombre» ${ }^{65}$, en donde, según Berger, se pasa del problema de la teodicea al problema de la antropodicea. Para justificar a Dios de toda causalidad respecto del mal, se desarrolla una antropología correlacionada con el orden instaurado por Dios, en donde el hombre genera el mal al orientarse hacia la inmanencia intramundana y no hacia la trascendencia divina. El autor insiste en que la pretendida mitigación de la sumisión inherente a la polaridad dialéctico-masoquista queda suavizada en la teodicea de la Cruz, en la figura del Cristo sufriente, tal y como señalaba Camus, y que en palabras de Berger consistiría en que: «Dios sufre en Cristo» ${ }^{66}$. Esta sentencia bergerina, remite a la teodicea weiliana, según la cual el amor de Dios queda patente en la cruz de Cristo. Weil insiste en que vemos a Cristo crucificado no como martir por la verdad, ni siquiera como el rey de la gloria ejecutado por un resentimiento envidioso. Para ella, Cristo es pura y simplemente un sufriente. Pero Cristo no deja que su condición cambie su amor al

65 Peter L. Berger, The Sacred Canopy. Elements of a Sociological Theory of Religion, op. cit., 78. Hammond está de acuerdo con Berger en lo referente al paso de la teodicea a la antropodicea: "Problems of theodicy (justification of God in the face of evil) have become problems of anthropodicy, says Berger. People ask now, "How can men act this way?" not, "How could God permit this?" (The Sacred Canopy. Elements of a Sociological Theory of Religion, op. cit., 78-79). We might agree that such a change is coming about. But in all aspects of religion? The Nazi wholesale murder of Jews is frequently cited as a phenomenon which has evoked psychological more than theological analysis». P. E. Hammond, «Peter Berger's sociology of religion. An appraisal», Soundings 52, (1964): 421.

66 Peter L. Berger, The Sacred Canopy. Elements of a Sociological Theory of Religion, op. cit., 78. 
Padre y al mundo que este ha creado, aunque contenga sufrimiento. Aunque se siente abandonado, lo acepta como la voluntad del Padre y ama incluso cuando parece que no hay nada que amar. No está lleno de resentimiento. En ello, sugiere Weil, se establece en último término un vínculo de amor perfecto entre Cristo abandonado y el Padre que está en el cielo. En el amor de Cristo, el amor de Dios se hace presente en el mundo. Es una teodicea sacrificial fundamentada en la concepción de un Dios amor que hace del sufrimiento una llamada al hombre para trascender el mal. La Cruz da que pensar, pues un Dios que sufre, desciende desde la trascendencia divina hasta la inmanencia humana. Aparece lo que Berger denominó, siguiendo a San Pablo, «locura de la cruz» y «mensaje de la cruz»:

Es un tema esencial del cristianismo, que los teólogos han denominado kenosis, la humillación de Dios; el mismo Dios que posee todos los poderes, que creó este mundo y todos los mundos posibles, asumió la forma y el destino de un hombre corriente, y de hecho, de un hombre que padecío las aflicciones más atormentadoras de la traición, la tortura, la desesperación y la muerte (...) la debilidad de Dios revela su auténtico poder, incluyendo el poder de triunfar sobre el pecado y sobre la muerte ${ }^{67}$.

La plausibilidad del cristianismo depende de la comprensión de esta teodicea de la cruz, del sufrimiento, frente a los constantes intentos desvalorizantes de tal teodicea. Volvemos, otra vez, a encontrar en esta reflexión una gran similitud entre el pensamiento de Berger y el de Simone Weil. La autora francesa también considera que el cristianismo tiene como esencia el sufrimiento, y lo expresa así: «La extrema grandeza del cristianismo procede del hecho de que no busca un remedio sobrenatural contra el sufrimiento, sino un uso sobrenatural del sufrimiento ${ }^{68}$. Es decir, para ella -lo mismo que para Berger- el conocimiento del cristianismo no implicaba liberarse del

67 Peter L. Berger, A far glory: The quest for faith in an age of credulity, op. cit., 6.

68 Simone Weil, A la espera de Dios, op. cit., 120. Berger considera que el «misticismo» es una forma subjetiva de experiencia de lo sobrenatural: «As to mysticism, it is certainly one important form of the experience of the supernatural, probably best defined as an avenue to the supernatural by deliberate inmersión in the "depths" of subjetive consciousness», en Peter L. Berger, «On the conceptualization of the supernatural and the sacred», op. cit., 36. 
sufrimiento, sino comprender que en la pura desdicha reside nuestro verdadero punto de encuentro con la inmensidad del amor de Dios.

Algunos de estos intentos de impugnación a esta legitimación religiosa son acontecimientos históricos tales como catástrofes naturales y sociopolíticas (terremoto de Lisboa de 1755, primera y segunda guerras mundiales, etc.). A partir de tales acontecimientos, la teodicea cristiana entra en una crisis de significado y de legitimación, a la vez que se rechaza la teodicea en cuanto «justificación de Dios» y se impugna también directa y sistemáticamente la bondad de la creación cristiana. Pero a raíz de tales acontecimientos históricos, señala Berger, de forma inesperada se produce el «giro kantiano». Es decir, el salto de la teodicea a la antropodicea, en donde, a partir de ahora, el problema del mal moral y físico es estudiado en conexión con la libertad del hombre. Aparecen las antinomias de la teodicea, gracias a las cuales el mal seguirá debiéndose a la naturaleza humana y Dios cae en una terrible impugnación de credibilidad si no es capaz de evitar ese mal natural. Todo esto va a llevar a una «negociación cognoscitiva» con la contemporaneidad secular dentro de un marco de referencia compartido. Consistía, pues, en un intento de armonizar la teodicea cristiana con la cosmovisión del mundo moderno, lo cual produjo la desintegración de dicha teodicea en la conciencia del hombre occidental, lo que Berger denominó «secularización de las conciencias» ${ }^{69}$.

Con el avance de la secularización en la época moderna, la pregunta ya no es cómo justificar la existencia de Dios en las debilidades humanas, sino cómo creer en el hombre a pesar de las deshumanidades practicadas. Antiguamente, ante una desgracia natural se inquiría: ¿Cómo Dios permitió eso? Ahora, con las guerras de exterminio entre grupos rivales, nos preguntamos: ¿Cómo los hombres son capaces de tantas barbaries?, ¿̇será que todavía podemos creer en el hombre? Caminaríamos así, señala Berger, de la Teodicea hacia la Antropodicea.

69 Peter L. Berger, The Sacred Canopy. Elements of a Sociological Theory of Religion, op. cit., 105-106. 
Berger argumenta que el momento culminante de la teodicea cristiana se encuentra en la teodicea social de la cristiandad medieval, que buscaba legitimar las desigualdades sociales. Así pues, el derrumbamiento de esta estructura de plausibilidad cristiana medieval llevó consigo la pérdida de plausibilidad de la teodicea cristiana: « $\mathrm{Si}$ la explicación cristiana del mundo ya no es válida, entonces tampoco la legitimación cristiana del orden social podrá mantenerse por mucho tiempo» ${ }^{70}$. Esto lleva a Berger a observar cómo la moderna filosofía de la historia parte del fracaso de las teodiceas cristianas. Se elimina el problema de Dios y el problema del hombre asume toda la responsabilidad en un proceso de emancipación teológicoantropológico, en una especie de despertar del sueño antropológico foucaultiano: «La muerte de Dios arrastra consigo la del bien y la del mal, la de la libertad y responsabilidad histórica, en una palabra, la idea del hombre del humanismo occidental ${ }^{71}$. Ahora, la historia y las acciones humanas son los principales medios de nomización del universo socialmente construido, son las configuraciones de los universos simbólicos de significación humana ${ }^{72}$.

Berger considera que la reestructuración del paradigma cosmológico-medieval obligó a considerar los problemas filosóficos concernientes al hombre y a su interpretación del universo, al igual que lo concerniente a la problemática de la relación entre el mundo y Dios. Así pues, el cosmos es comprensible porque está en función de la vida humana, debido a una nueva perspectiva del teísmo filosófico cristiano, según el cual, existen razones de credibilidad que hacen plausible una interpretación filosófica antropocéntrica: 1) el mundo existe en función del hombre y, 2) el hombre no es el fruto del azar.

72 Según Hegel, el carácter escatológico-inmanente del concepto de Dios, solo puede ser explicado desde la historia, y con más exactitud desde la historia «secularizada» de las religiones. Según el propio Hegel, la historia es teodicea (justificación de la presencia de Dios en el mundo), aunque debe entenderse como antropodicea, o como diría Bloch «mesianismo ateo» o «mesianismo humanoescatológico». «La historia universal es la realización del espíritu, la justificación de Dios en la historia», en G. W. F. Hegel, Lecciones sobre la filosofía de la historia universal (Madrid: Revista de Occidente, 1974), 701. 
Berger va a encontrar en Camus un exponente de lo que representa esta crisis de la teodicea cristiana, pues la intención de este es la de una pretensión de mantenerse en una rebelión sin claudicar, sin deshumanizarse ni reconciliarse con el sufrimiento a pesar de la permanente derrota. Camus representa la apertura a una perspectiva estrictamente cristiana y a su fracaso histórico en el intento de cambiar la historia. Es decir, el autor existencialista es el representante específico de lo que representa la crisis de plausibilidad de la teodicea cristiana y su proyección social.

La intención de Berger al exponer las diferentes constelaciones históricas de teodiceas es la de desvelar en líneas generales «cómo el hombre adopta posiciones existenciales y teóricas en relación a los aspectos anómicos de su experiencia, y cómo diferentes sistemas religiosos se relacionan con esta empresa de nomización ${ }^{73}$. El interés del autor se centra en hacer ver que el problema de la teodicea es un elemento referencial dentro de la empresa humana de construcción y conservación del mundo desempeñada por la religión, pues las amenazantes fuerzas anómicas (caos, muerte, etc.) están siempre intentando deslegitimar la realidad socialmente construida y nómicamente establecida ${ }^{74}$. Por tanto, el autor cree que la teodicea es inherente a las legitimaciones y cosmovisiones religiosas en tanto que pretenden «un intento de pactar» con la anomia, asegurando la perdurabilidad del nomos a lo largo de la historia colectiva y la biografía experiencial e individual. De esta forma, Berger piensa en la teodicea en el sentido de legitimación religiosa de los fenómenos anómicos, esencialmente de las situaciones marginales -específicamente la muerte en sentido heideggeriano- que ponen en duda la realidad cotidiana, y ante las cuales debe establecerse una explicación y una justificación de las mismas:

73 Peter L. Berger, The Sacred Canopy. Elements of a Sociological Theory of Religion, op. cit., 80.

74 «El problema de la teodicea ha sido resuelto de varias maneras. Estas soluciones guardan estrecha relación tanto con las formas asumidas del concepto de Dios como con la noción de pecado y salvación cristalizada en los grupos sociales concretos», Max Weber, The Sociology of Religion (Boston: Beacon Press, 1964), 139. 
Todo orden humano es una comunidad frente a la muerte. La teodicea representa el intento de pactar con esta. Cualquiera que sea el destino de una religión histórica, o de la religión como tal, podemos estar seguros de que la necesidad de este intento, persistirá a lo largo de la vida de las sociedades, mientras los hombres sigan muriendo, y tengan que encontrarle una significación a este hecho ${ }^{75}$.

La teodicea está enraizada dentro del proceso de socialización humana en tanto que dadora y fundamentadora de sentido, de la misma forma que sus funciones explicativas y justificativas tanto a nivel social como individual son análogas en la medida en que sus pretensiones son las de integrar la anomia dentro del nomos social.

\section{Bibliografía}

Baum, Gregory. Religión y alienación. Madrid: Cristiandad, 1980.

Berger, Peter L. A far glory: The quest for faith in an age of credulity. New York: Free Press, 1992.

A rumor of angels: Modern society and the rediscovery of the supernatural. New York: Garden City Doubleday, 1969.

. «Charisma and religious innovation: the social location of israelite prophecy», American Sociological Review 6, Vol. 28 (1963): 940-950.

. "Motif messianique et processus social dans le Behaisme», Archives de Sociologie des Religions 4, Vol. 4 (1967): 93-107.

. "On the conceptualization of the supernatural and the sacred». Dialog 17, 1978: 36-42.

. Questions of faith. A skeptical affirmation of Christianity. New York: Blackwell Publishing, 2004.

. "Reflections on law and order», Christianity and Crisis 21, Vol. XXVIII (1968): 298-299.

75 Peter L. Berger, The Sacred Canopy. Elements of a Sociological Theory of Religion, op. cit., 80. 
. The sacred canopy: elements of a sociological theory of religion. New York: Garden City Doubleday, 1967. . The social reality of religion. Londres: Faber \& Faber, 1969.

Bloch, Ernst. El ateísmo en el cristianismo. Madrid: Aguilar, 1983.

Camus, Albert. The rebeld. New York: Vintage, 1956.

Durkheim, Émile. Las formas elementales de la vida religiosa. Madrid: Alianza Editorial, 1993.

Estrada, Juan Antonio. La imposible teodicea. Madrid: Trotta, 1978.

Hammond, P. E. «Peter Berger's sociology of religion. An appraisal». Soundings 52, (1964): 415-424.

Hegel, G. W. F. Lecciones sobre la filosofía de la historia universal. Madrid: Revista de Occidente, 1974.

Kant, Inmanuel. La religión dentro de los límites de la mera razón. Madrid: Alianza, 1981.

Moltmann, Jürgen. Teología de la esperanza. Salamanca: Sígueme, 1989.

Rovira, Rogelio. Sobre el fracaso de todo ensayo filosófico en la teodicea. Madrid: Universidad Complutense, Facultad de Filosofía, 1992.

San Agustín. «De fide et símbolo». En Obras completas XXXIx. Madrid: Biblioteca de Autores Cristianos, 1988.

Weber, Max. Economía y sociedad. México: Fondo de Cultura Económica, 1994.

. Ensayos sobre sociología de la religión I. Madrid: Taurus 1983.

. «La ética protestante y el espíritu del capitalismo». En Ensayos sobre sociología de la religión I. Madrid: Taurus, 1983. Y La ética protestante y el espíritu del capitalismo. Barcelona: Península, 1979. 
. Sociología de la religión. Madrid: Itsmo, 1997.

. The sociology of religión. Boston: Beacon Press, 1964.

Weil, Simone. A la espera de Dios. Madrid: Trotta, 2000.

. Cuadernos II. Madrid: Trotta, 1972.

. La gravedad y la gracia. Madrid: Trotta, 1998.

Weissmahr, Béla. Teología natural. Barcelona: Herder, 1986.

Recibido: 22 de enero de 2014

Arbitrado: 23 de febrero de 2014 